\title{
Produção de leite e desempenho dos bezerros de vacas Nelore e mestiças ${ }^{1}$
}

\section{Vítor Corrêa de Oliveira ${ }^{2}$, Carlos Augusto de Alencar Fontes ${ }^{3}$, João Gomes de Siqueira ${ }^{4}$, Alberto Magno Fernandes ${ }^{5}$, Nivaldo de Faria Sant Ana $^{6}$, Alberto Chambela Neto ${ }^{7}$}

1 Projeto parcialmente financiado pela FAPERJ e pelo CNPq

2 Mestre em Produção Animal.

${ }^{3}$ LZNA/CCTA/UENF, bolsista do CNPq.

${ }^{4}$ Doutor em Produção Animal.

5 LZNA/CCTA/UENF.

${ }^{6}$ Doutorando em Produção Animal (LZNA/CCTA/UENF).

7 Mestrando em Produção Animal (LZNA/CCTA/UENF).

RESUMO - O trabalho foi realizado com o objetivo de avaliar as curvas de lactação de vacas Nelore e mestiças F1 LimousinNelore (LN) e Simental-Nelore (SN) e o desempenho de suas progênies. Foram utilizadas 13 vacas de cada grupo genético, com 5 a 9 anos de idade, e as suas respectivas crias. A partir do 15ํ dia após o parto até a desmama dos bezerros (210 dias), as vacas foram mantidas com suas crias em baias individuais. No arraçoamento procurou-se atender $100 \%$ das exigências de mantença e lactação das vacas; a mesma ração foi fornecida aos bezerros a partir dos 90 dias de idade visando atender no máximo 30\% de suas exigências nutricionais. A ração foi formulada com 30\% de concentrado e 70\% de silagem, na MS. A produção de leite das vacas foi determinada mensalmente pelo método da diferença de peso dos bezerros. Por meio de um modelo não-linear, estimaram-se o tempo necessário para as vacas atingirem o pico de lactação, a produção no pico, a persistência de produção de leite e as produções total e média diária. As vacas Nelore tiveram, em comparação às mestiças, menores produções no pico de lactação, total e média diária, mas apresentaram maior persistência de lactação. As produções no pico de lactação, total e média diária, nas vacas SN foram maiores que nas vacas LN, no entanto, não houve diferença entre esses grupos quanto à persistência de lactação. Os bezerros das vacas Nelore apresentaram menores ao nascer e à desmama e ganharam menos peso no período de aleitamento em comparação aos de vacas mestiças, que não diferiram entre si. Vacas mestiças têm maior habilidade materna que vacas Nelore.

Palavras-chave: curva de lactação, Limousin, Simental

\section{Milk production and performance of calves from Nellore and crossbred cows}

ABSTRACT - The research was carried out to evaluate the lactation curves of Nellore and Crossbred F1 Limousin-Nellore (LN) and Simmental-Nellore (SN) cows and the performance of the progeny. Thirteen cows from each breed group, with age ranging from 5 to 9 years, and the respective calves were used. From 15 days after calving until weaning of the calves (210 days), the cows and calves were kept in individual pens. The nutritional requirements of the cows for maintenance and lactation were met. The same ration was offered to the calves from the 90 days of age, in limited amounts to supply $30 \%$ of the nutritional requirements. The ration was formulated with $30 \%$ of concentrate and $70 \%$ of silage, DM basis. Monthly, milk production of the cows was estimated, utilizing the weigh-suckle-weigh method. By means of nonlinear model, it was estimated the time needed for the cows to reach the peak of lactation, the production at the peak of lactation; the persistence of milk production and total and daily average milk production. Nellore cows showed lower production at the peak of lactation, total and daily average milk production, but higher persistency than crossbred cows. The productions in the lactation peak, total and daily average, in cows SN, were higher than in cows LN, however, no difference was observed between these groups for lactation persistence. Calves from Nellore cows had lower birth weight, weaning weight and preweaning weight gain than those from crossbred cows. There was no difference between calves from the two crossbred groups. It is concluded that crossbred cows have higher maternal ability than Nellore cows.

Key Words: lactation curve, Limousin, Simmental 


\section{Introdução}

O genótipo da vaca é um dos fatores que mais influenciam o peso à desmama do bezerro de corte, pois determina parcialmente seu genótipo e define o potencial de produção de leite da vaca, característica fundamental da habilidade materna.

Segundo Rutledge et al. (1971), aproximadamente 60\% da variação no peso do bezerro aos 205 dias de idade pode ser atribuída à produção de leite materno. Os valores de correlação entre a produção de leite da vaca e o ganho de peso do bezerro são mais altos quando os bezerros não recebem suplemento alimentar no período de aleitamento, especialmente quando ocorre limitação qualitativa e/ou quantitativa de forragem.

Avaliando os efeitos da produção de leite sobre o desenvolvimento de bezerros Canchim, Alencar (1987) verificou que a produção de leite da vaca determinou uma porção significativa da variação nos pesos e ganhos totais de peso da cria. Todavia, esse autor constatou que os bezerros que consumiram mais leite foram menos eficientes na sua utilização. Ferrell \& Jenkins (1982), comparando vacas mestiças de diferentes portes e produções de leite, verificaram que, em alguns casos, vacas de maior porte desmamaram bezerros mais leves por produzirem menos leite.

Tem-se verificado em animais mestiços efeito de heterose na produção de leite (Notter et al., 1978; Restle et al., 2005), o que contribuiu para o maior peso à desmama das progênies de vacas F1 em relação aos bezerros F1 filhos de vacas puras (Peakcock et al., 1977). Vacas mestiças proporcionam ainda ao feto ambiente uterino favorável ao desenvolvimento pré-natal, o que resulta em crias maiores ao nascer em comparação a vacas puras, especialmente da subespécie Bos indicus (Jenkins et al., 1991), o que reflete no peso à desmama.

Ao utilizar animais com maior potencial genético para produção de leite, é necessário considerar as condições nutricionais locais para não prejudicar características relacionadas à eficiência reprodutiva, como duração do anestro pós-parto e do período de serviço, que afetam o intervalo de partos e a fertilidade. Assim, para determinada disponibilidade de energia, a produção de leite das vacas não pode interferir no suprimento dos nutrientes necessários à manutenção de índices ideais de reprodução (Willham, 1972).

Este trabalho foi realizado para avaliar a curva de lactação de vacas Nelore e mestiças F1 Limousin-Nelore e SimentalNelore e o desempenho das progênies até a desmama.

\section{Material e Métodos}

A pesquisa foi realizada no Laboratório de Zootecnia e Nutrição Animal (LZNA) da Universidade Estadual do Norte Fluminense - UENF, anexa ao Colégio Agrícola Antônio Sarlo, em Campos dos Goytacazes, RJ.

Foram utilizadas 39 vacas adultas recém-paridas com idade de 5 a 9 anos de idade - 13 de cada grupo genético estudado Nelore (N), F1 Simental-Nelore(SN) e F1 LimousinNelore (LN) - e seus bezerros, filhos de touros Nelore, Simental e Brahman, respectivamente, escolhidas ao acaso entre as vacas gestantes de rebanhos comerciais, procurando uniformidade quanto à idade, ao tempo de gestação, ao porte e ao escore de condição corporal, nos três grupos genéticos. As vacas foram transportadas para as dependências da UENF aproximadamente um mês antes da data prevista para o parto e foram mantidas em pastejo rotativo em piquetes de capim-elefante (Pennisetum purpureum CV. Napier), onde ocorreram os partos.

Quinze dias após a data individual do parto, cada vaca e sua respectiva cria foram transferidas para baias individuais, onde foram mantidas até o bezerro atingir 210 dias de idade. As baias tinham área de $12 \mathrm{~m}^{2}$, metade coberta com telhas de amianto, providas de cochos e bebedouros individuais. Na extremidade de cada baia, oposta ao cocho de alimentação da vaca, instalou-se um creep feeding com área de $1,8 \mathrm{~m}^{2}$ contendo comedouro com acesso apenas ao bezerro. Visando à adaptação dos animais, o fornecimento da ração experimental foi feito paulatinamente, de modo que, durante a primeira semana, o capim-elefante foi fornecido sem picar, em quantidades decrescentes.

Ao iniciarem o consumo de ração, os bezerros foram contidos por cabrestos, de forma a não alcançarem o cocho da vaca, mas sem restringir-lhes o acesso ao creep feeding e possibilitando-lhes amamentação voluntária.

O arraçoamento foi feito de forma a atender $100 \%$ das exigências individuais para mantença e produção de leite das vacas, de acordo com as normas do NRC (2000). Foram utilizadas seqüencialmente, durante a primeira e a segunda metade do período experimental, duas rações, ambas contendo $70 \%$ de volumoso e $30 \%$ de concentrado na MS (Tabelas 1 e 2). Na primeira semana, incluiu-se a silagem de milho como volumoso e, na segunda, a silagem de sorgo. Nos dois períodos, utilizou-se o mesmo concentrado misturado às silagens, constituído de farelo de soja (10,0\%), milho moído (66,5\%), uréia(3,5\%)e farelo de trigo (20,0\%), namatérianatural.

Para determinação das quantidades de ração a serem oferecidas a cada vaca, foram calculados os teores de energia metabolizável (EM) das rações, com base em dados 
Tabela 1 - Proporções de silagem de milho e concentrado e conteúdos de MS, PB, FDN, Ca, P, energia digestível (ED) e energia metabolizável (EM) na ração completa fornecida na primeira fase do período experimental

Table 1 - Proportions of corn silage and concentrate, and contents of DM, CP, NDF, Ca, P, digestible energy (DE) and metabolizable energy (ME) in complete diet used in the first phase of the experimental period

\begin{tabular}{lcc}
\hline Ingrediente & Proporção (\%MS) & Composição (\%MS) \\
Ingredient & Proportion $(\% D M)$ & Composition (\%DM)
\end{tabular}

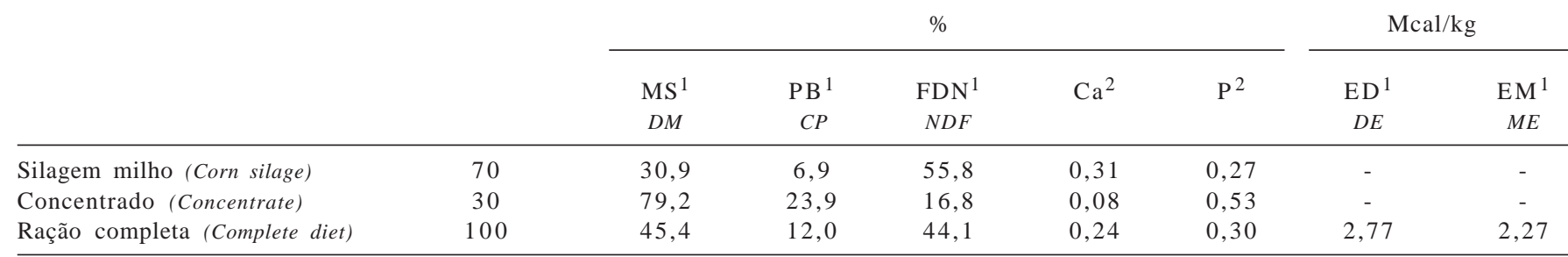

${ }^{1}$ Valores determinados experimentalmente (Values obtained experimentaly).

2 Valores obtidos em tabela (NRC, 2000) (Values from feed tables - NRC, 2000).

Tabela 2 - Proporções de silagem de sorgo e concentrado e conteúdos de MS, PB, FDN, Ca, P, energia digestível (ED) e energia metabolizável (EM) na ração completa utilizada na segunda fase do período experimental

Table 2 - Proportions of sorghum silage and concentrate, and contents of DM, CP, NDF, Ca, P, digestible energy (DE) and metabolizable energy (ME) in complete diet used in the second phase of the experimental period

\begin{tabular}{|c|c|c|c|c|c|c|c|c|}
\hline \multirow[t]{3}{*}{$\begin{array}{l}\text { Ingrediente } \\
\text { Ingredient }\end{array}$} & \multirow[t]{3}{*}{$\begin{array}{c}\text { Proporção (\%MS) } \\
\text { Proportion (\%DM) }\end{array}$} & \multicolumn{7}{|c|}{$\begin{array}{c}\text { Composição (\%MS) } \\
\text { Composition (\%DM) }\end{array}$} \\
\hline & & \multicolumn{5}{|c|}{$\%$} & \multicolumn{2}{|c|}{ Mcal/kg } \\
\hline & & $\begin{array}{l}\mathrm{MS}^{1} \\
D M\end{array}$ & $\begin{array}{c}\mathrm{PB}^{1} \\
C P\end{array}$ & $\begin{array}{l}\mathrm{FDN}^{1} \\
N D F\end{array}$ & $\mathrm{Ca}^{2}$ & $\mathrm{P}^{2}$ & $\begin{array}{c}\mathrm{ED}^{1} \\
D E\end{array}$ & $\begin{array}{r}\mathrm{EM}^{1} \\
\mathrm{ME}\end{array}$ \\
\hline Silagem sorgo (Sorghum silage) & 70 & 26,2 & 6,5 & 50,1 & 0,40 & 0,20 & - & - \\
\hline Concentrado (Concentrate) & 30 & 79,2 & 23,9 & 16,8 & 0,08 & 0,53 & - & - \\
\hline Ração completa (Complete diet) & 100 & 42,1 & 11,7 & 40,1 & 0,30 & 0,30 & 2,70 & 2,21 \\
\hline
\end{tabular}

1 Valores determinados experimentalmente (Values obtained experimentaly).

2 Valores obtidos em tabela (NRC, 2000) (Values from feed tables - NRC, 2000).

tabelados (NRC, 2000). A seguir, utilizando-se as equações propostas por Garrett em 1980, apresentadas pelo NRC (2000), foram calculados os conteúdos de energia líquida para mantença e ganho das duas rações. Posteriormente, foram determinadas as quantidades de ração necessárias para atender 100\% das exigências individuais de EM (para mantença e lactação), de acordo com o NRC (2000). As quantidades encontradas atenderam, ao mesmo tempo, às exigências de nitrogênio dos microrganismos ruminais e de proteína metabolizável das vacas.

As quantidades individuais de ração oferecidas foram ajustadas a cada 30 dias, de acordo com o peso corporal e a produção de leite das vacas. Além disso, ajustes foram feitos de acordo com as variações no teor de MS da silagem, buscando manter constantes as proporções de concentrado:volumoso. O alimento foi fornecido diariamente, às 7h30, após remoção das sobras do dia anterior, as quais foram pesadas e amostradas.

Os conteúdos de energia digestível (ED) das duas rações completas foram determinados em ensaios de digestibilidade utilizando-se as vacas experimentais. O conteúdo de EM foi calculado a partir da ED utilizando-se o coeficiente 0,82 (NRC, 2000), o que possibilitou calcular o consumo de EM de cada vaca. O concentrado (acrescentado de 100 g de mistura mineral comercial) e a silagem fornecidos a cada vaca foram misturados diretamente no cocho no momento do fornecimento.

Amostras diárias de silagem foram retiradas e armazenadas em congelador, enquanto o concentrado foi amostrado semanalmente. Foram constituídas amostras compostas das silagens e do concentrado, referentes a períodos de 28 dias, para análises posteriores.

A partir dos 90 dias de idade, os bezerros foram alimentados com a mesma ração oferecida às vacas, limitando-se o consumo ao máximo de MS $1 \mathrm{~kg} / \mathrm{dia}$, de forma a não ultrapassar 30\% de suas exigências nutricionais, o que possibilitou avaliar a influência do nível de produção de leite da vaca sobre o desempenho da cria. A ração foi oferecida aos bezerros em cochos protegidos fora do alcance da vaca (creep feeding).

A produção de leite individual foi estimada mensalmente pelo método de diferença dos pesos dos bezerros 
antes e após a amamentação (Cundiff et al., 1974). No dia anterior à avaliação, às $13 \mathrm{~h}$, os bezerros foram separados das vacas e às 19h, foram reunidos com as mães durante 20 minutos para mamar e esgotar o leite das glândulas mamárias. Em seguida, os bezerros foram separados das vacas até as $7 \mathrm{~h}$ do dia seguinte, quando foi estimada a produção de leite correspondente ao período de 12 horas. Para isso, os bezerros foram pesados e colocados para mamar durante 20 minutos e novamente pesados. As pesagens foram feitas no menor tempo possível para minimizar erros decorrentes da excreção de fezes e de urina entre as duas pesagens. A produção de leite foi ajustada para o período de secreção de 24 horas.

Nas análises referentes à produção de leite, inicialmente, foram ajustadas curvas individuais de lactação para as vacas dos três grupos genéticos, utilizando-se o modelo proposto por Jenkins \& Ferrell (1984):

$$
\mathrm{Y}_{(\mathrm{n})}=\mathrm{n} \times\left(\mathrm{ae}^{\mathrm{kn}}\right)^{-1} \text {, }
$$

em que $\mathrm{Y}_{(\mathrm{n})}=$ produção de $24 \mathrm{~h}$ durante a enésima semana pós-parto; $\mathrm{a}$ = parâmetro de escala da curva; $\mathrm{k}$ = parâmetro da forma da curva, que indica persistência de lactação; $n$ = tempo de lactação em semanas.

As estimativas dos parâmetros a e $\mathrm{k}$ foram utilizadas, conforme Jenkins \& Ferrell (1984), para calcular três valores descritivos característicos da curva de lactação:

$$
\begin{gathered}
\mathrm{S}=(1 / \mathrm{k}) ; \mathrm{P}=(1 / \mathrm{ake}) ; \mathrm{T}_{210}=-7 \times(\mathrm{a} \times \mathrm{k})^{-1} \times\left(30 \times \mathrm{e}^{-30 \mathrm{k}}\right) \\
\left.+\left(\mathrm{k}^{-1} \times \mathrm{e}^{-30 \mathrm{k}}\right)-\mathrm{k}^{-1}\right),
\end{gathered}
$$

em que: $\mathrm{S}=$ tempo de pico de lactação; $\mathrm{P}=$ produção no momento do pico de lactação; $T_{210}=$ produção total em 210 dias de lactação.

A persistência de lactação (L) foi definida como o decréscimo linear diário na produção de leite entre as épocas do pico de lactação (P) e da desmama (Jenkins et al., 2000):

$\mathrm{L}=(\mathrm{P}-$ produção no dia da desmama $) / \mathrm{n} \underline{0}$ de dias entre o pico e o final da lactação.

Os parâmetros da curva de lactação a e k e as variáveis derivadas estimados para cada vaca foram considerados variáveis dependentes e submetidos à analise de variância, de acordo com o modelo que incluiu os efeitos de grupo genético, sexo do bezerro, covariável idade da vaca e erro aleatório, empregando-se o método de mínimos quadrados do procedimento do GLM do SAS.

As análises dos dados referentes aos pesos dos bezerros ao nascer, à desmama e ao ganho de peso dos bezerros foram feitas segundo modelo que incluiu os efeitos de grupo genético, sexo do bezerro, interação sexo $\times$ grupo genético, covariável idade da vaca e erro aleatório. Os pesos dos bezerros à desmama, antes de serem submetidos à análise de variância, foram ajustados para a idade constante de 210 dias.
As comparações entre os três grupos genéticos foram feitas por meio dos contrastes ortogonais entre vacas Nelore e mestiças, em conjunto, e entre os dois grupos mestiços.

\section{Resultados e Discussão}

Não houve efeito da idade da vaca e do sexo do bezerro sobre as curvas de lactação, o tempo de pico de lactação, a produção no pico, a persistência, a produção total e a produção média diária de leite (Tabela 3). Vários autores têm observado efeito de idade da vaca sobre a produção de leite de gado de corte (Dawson et al., 1960; Melton et al., 1967; Jeffery et al., 1971; Rutledge et al., 1971; Neville et al., 1974; Notter et al., 1978) e os resultados comprovam que a produção de leite aumenta com a idade e tende a se estabilizar entre 5 e 10 anos de idade.

A ausência de influência da idade da vaca sobre os parâmetros e as variáveis relacionados à produção de leite está de acordo com resultados descritos na literatura, uma vez que foram utilizadas vacas adultas com idades entre 5 e 9 anos. Resultado semelhante foi relatado por Jenkins \& Ferrell (1992), que, durante quatro anos, avaliaram 431 lactações de 179 vacas de nove raças diferentes (incluindo Limousin e Simental) com idades entre 4 e 8 anos e verificaram que não houve influência da idade da vaca sobre os parâmetros da curva de lactação e as produções de leite total e média diária.

Neste sentido, o NRC (2000) afirma, com base nos resultados de diversos autores, que as produções de leite de vacas de corte de 2 e 3 anos, são, respectivamente, 26 e $12 \%$ mais baixas que aquelas de vacas de 4 anos de idade ou mais velhas e que não existe diferenças entre idades superiores a 4 anos. No Brasil, Rosado (1991) mediu a produção de leite de vacas Nelore F1 Fleckvieh-Nelore e F1 Chianina-Nelore por dois anos consecutivos e verificou que a produção de leite em vacas primíparas foi menor que em vacas com duas ou mais crias. Esse autor não observou, no entanto, diferenças entre vacas de duas ou mais crias. Por outro lado, Alencar et al. (1985) relataram não haver influência da ordem de parição (1 a 5) sobre a produção de leite de vacas Canchim.

A influência do sexo do bezerro sobre a produção de leite de vacas de corte tem sido enfocada em várias pesquisas, no entanto, há controvérsia nos resultados. Alencar et al. (1988) e Rosado (1991) verificaram maior produção de leite em vacas amamentando bezerros machos. Reynolds et al. (1978) e Alencar et al. (1985) constataram ausência de influência do sexo do bezerro sobre a produção de leite e Robison et al. (1978) observaram maior produção de vacas amamentando fêmeas. 
Tabela 3 - Níveis descritivos de probabilidade para o erro tipo I, associados aos contrates ortogonais entre vacas Nelore e mestiças $(\mathrm{N} \times \mathrm{M})$ e entre mestiças F1 Simental-Nelore e F1 Limousin-Nelore $(\mathrm{SN} \times \mathrm{LN})$, referentes aos parâmetros a e k e suas variáveis relacionados à curva de lactação e respectivas médias para os diferentes grupos genéticos

Table 3 - Levels of probability for error type I, associated to orthogonal contrasts between nellores and crossbred cows (NxCB) and between F1 SimmentalNellore and F1 Limousin-Nellore cows ( $S N \times L N$ ), referring to the parameters (a and $k$ ) and to derived variables related to lactation curve, and respective means for the different genetic groups

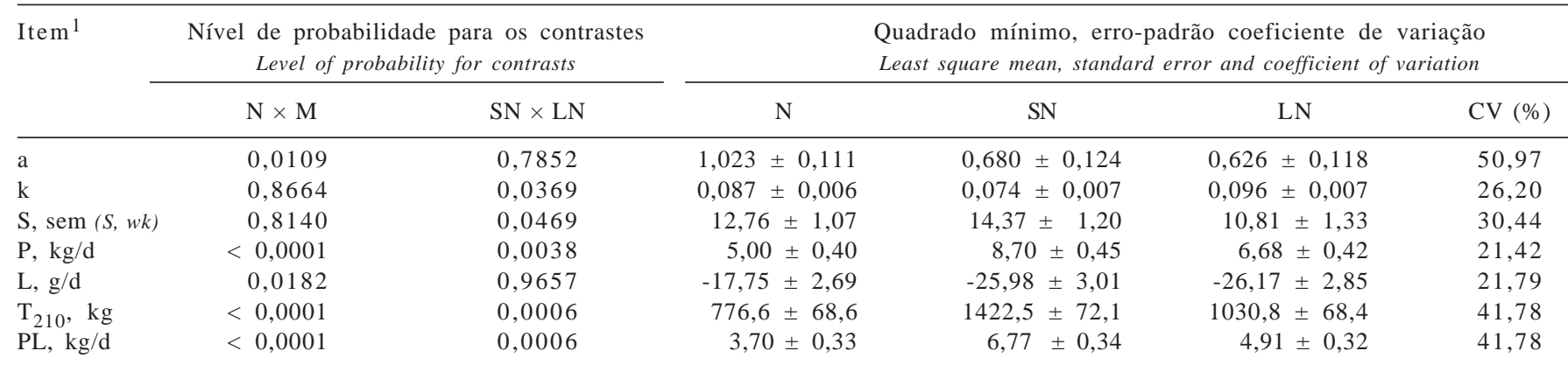

1 em que (given): $\mathrm{a}=$ parâmetro de escala da curva (parameter of scale of lactation curve); $\mathrm{k}=$ parâmetro de forma da curva (parameter of shape of curve); $\mathrm{S}=$ pico de lactação (time of peak lactation); P = produção de leite no pico de lactação (milk production at lactation peak); $\mathrm{T}_{210}=$ produção de leite total em 210 dias (210 day milk yield); PL = produção de leite diária (mean daily milk production); L = redução diária na produção de leite do pico de lactação à desmama, 210 dias (daily decrease in milk production from lactation peak to weaning, 210 days).

As vacas Nelore tiveram maior valor $(\mathrm{P}<0,05)$ para o parâmetro "a” (de escala), mas não diferiram das mestiças (P>0,05) quanto ao parâmetro "k" (de forma) da curva de lactação e quanto à época de ocorrência do pico de lactação. As vacas Nelore mestiças tiveram maior persistência de lactação (menor redução da produção), mas menores produções de leite no pico de lactação, total e média diária $(\mathrm{P}<0,05)$.

As vacas $\mathrm{SN}$, em relação às $\mathrm{LN}$, não diferiram $(\mathrm{P}>0,05)$ quanto ao parâmetro "a” da curva e quanto à persistência de lactação (L), mas apresentaram menor valor $(\mathrm{P}<0,05)$ do parâmetro " $\mathrm{k}$ " e maior $(\mathrm{P}<0,05)$ tempo para atingir o pico de lactação e as produções de leite no pico, total e média diária.

A raça Nelore tem sido considerada de baixa aptidão leiteira. Têm-se observado em vacas Nelore produções de leite mais baixas em comparação à de animais de raças compostas ou animais mestiços Europeu-Zebu, embora seja pequeno o número de trabalhos nacionais em que se determinou a produção de leite durante todo o período de aleitamento. Assim, Alencar et al. (1988), com base em medições feitas aos 30 e 120 dias de lactação, estimaram para vacas primíparas Nelore e Canchim mantidas em pastagem de capim-colonião produções de 655 e 972 kg, respectivamente, em 210 dias de lactação.

De forma semelhante à desta pesquisa, Calegare (2004) observou maior produção de leite em vacas F1 SimentalNelore em comparação a vacas Nelore e vacas F1 obtidas por cruzamento entre animais de raças de corte com Nelore. Esse autor estimou as produções de leite, em 180 dias de lactação utilizando resultados de avaliações aos 52, 66, 94, 122 e 178 dias pós-parto e encontrou produções de 641,5; 829,1; 969,9 e 1151,7 kg para vacas Nelore, F1 Canchim-Nelore, F1 AngusNelore e F1 Simental-Nelore, respectivamente.
A maior produção de leite das vacas mestiças EuropeuZebu em relação às Nelore está relacionada, basicamente, ao efeito aditivo de genes proporcionado por raças cruzantes com maior aptidão leiteira e ao efeito de heterose ocasionado pelas mestiças. A maior aptidão leiteira da raça Simental em relação à Limousin foi demonstrada por Jenkins \& Ferrell (1992), que verificaram produções no pico de lactação de 10,9 e 9,5 kg/dia para as duas raças, respectivamente.

Efeito positivo da heterose sobre a produção de leite foi verificado por Reynolds et al. (1967), Cundiff et al. (1974) e Notter et al. (1978). No Brasil, a importância da heterose foi registrada por Restle et al. (2005), que mediram as produções de leite de vacas Nelore, Charolês e F1 das duas raças e relataram valores de heterose de 31,7 e 65,0\% para produções de leite aos 14 e 70 dias de lactação.

Neste trabalho, as curvas de lactação obtidas para os três grupos genéticos (Figura 1) indicam que nas vacas SN a produção foi mais elevada, nas Nelore as produções foram mais baixas e nas vacas LN foram intermediárias, no entanto, nas vacas $L N$ a persistência de lactação foi menor. Ao avaliarem as curvas de lactação de vacas Nelore, Rosado (1991) e Alencar et al. (1988) observaram redução linear da produção de leite de acordo com o período de lactação e não constataram a existência de pico de lactação. Fontes (1985) observou em vacas de corte obtidas por cruzamento de touros Brahman e Romana Red com vacas Angus e F1 Angus-Brown Swiss a ocorrência de pico de produção próximo à 10 a semana de lactação.

O NRC (2000), com base na revisão de trabalhos dirigidos ao estudo da produção de leite de vacas de corte de diferentes grupos genéticos, estabeleceu que o pico de produção ocorre com 8,5 semanas de lactação. Neste trabalho, o pico de produção foi atingido mais tarde, entre 10,8 (vacas 
LN) e 14,3 semanas (vacas SN). Resultados mais próximos aos observados neste trabalho foram verificados por Jenkins \& Ferrell (1992), que adotaram o mesmo modelo não-linear para descrever a curva de lactação e constataram a ocorrência de pico de lactação entre 8,8 e 11,1 semanas pós-parto em vacas de corte pertencentes a nove diferentes raças, inclusive a Limousin e a Simental. A maioria dos resultados obtidos na literatura indica que vacas de corte, de forma semelhante às raças leiteiras, apresentam durante a lactação um pico de produção aparentemente mais tardio que o observado nas raças leiteiras.

A análise de variância revelou não haver efeito $(\mathrm{P}>0,05)$ da idade da vaca sobre o peso dos bezerros ao nascer, o peso à desmama e o ganho de peso no período de aleitamento. A ausência de influência da idade da vaca sobre os pesos e ganhos de peso dos bezerros do nascimento à desmama pode ser atribuída ao fato de que todas as vacas apresentavam, no início do experimento, idade entre 5 e 9 anos, pois neste intervalo a idade da vaca não influencia a produção de leite e o peso ao nascer dos bezerros.

O sexo do bezerro também não influenciou $(\mathrm{P}>0,05) \mathrm{o}$ peso ao nascer, o peso à desmama e o ganho de peso durante a fase de aleitamento. Não foi observado $(\mathrm{P}>0,05)$ efeito de interação de grupo genético e sexo do bezerro. Os bezerros machos pesaram 36,0 $\pm 1,9 \mathrm{~kg}$ ao nascer, $168,5 \pm 6,1 \mathrm{~kg}$ à desmama e ganharam $0,65 \pm 0,03 \mathrm{~kg} / \mathrm{dia}$. Nas fêmeas os valores observados foram $33,7 \pm 1,5 ; 165,7 \pm 4,8$; e 0,66 $\pm 0,02 \mathrm{~kg}$, respectivamente.

Alencar (1989) não observou efeito do sexo do bezerro sobre os ganhos de peso de bezerros Canchim em períodos sucessivos de 30 dias do nascimento à desmama, entretanto,

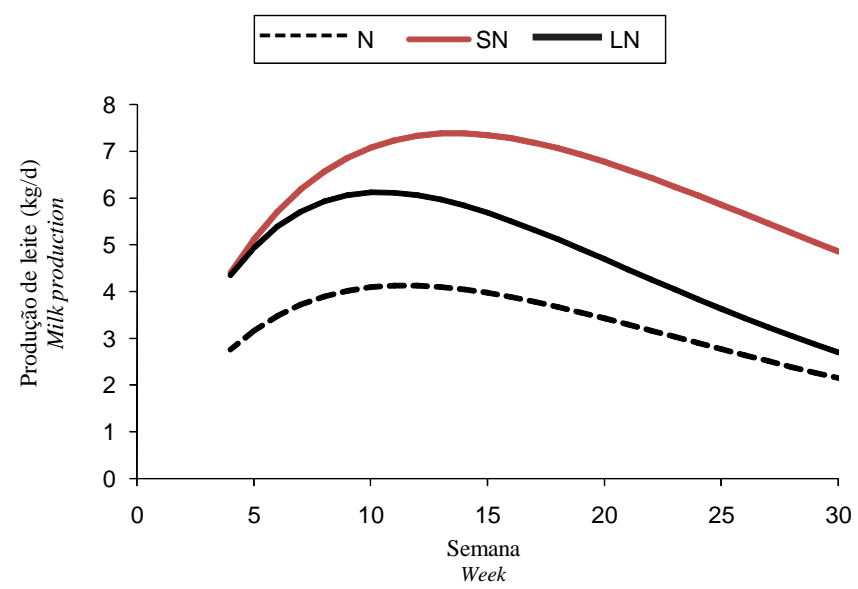

Figura 1 - Curvas de lactação de vacas Nelores (N), F1 SimentalNelore (SN) e F1 Limousin-Nelore (LN), ajustadas conforme modelo proposto por Jenkins \& Ferrell (1984).

Figure 1 - Lactation curves of Nellore (N), F1 Simmental-Nelore (SN) and F1 Limousin-Nellore (LN), adjusted according to model proposed by Jenkis \& Ferrell (1984). verificou maior ganho em machos Nelore em relação às fêmeas da mesma raça em três dos sete períodos avaliados. Jenkins \& Ferrell (2004), trabalhando com vacas mestiças obtidas por cruzamento de matrizes Angus e Hereford com touros das raças Angus, Hereford, Brahman, Boran e Tuli, também não verificaram efeito do sexo do bezerro sobre o ganho de peso durante o aleitamento. Entretanto, os bezerros machos nasceram mais pesados que as fêmeas (42,6 vs 40,0 kg) e, por isso, apresentaram maior peso à desmama.

Por outro lado, freqüentemente pesquisadores têm verificado em bezerros machos maior peso ao nascer, peso à desmama e ganho de peso na fase de aleitamento (Rosado, 1991; Euclides Filho et al., 1995; Cubas et al., 2001). Durante a fase de aleitamento, é ainda pequena a influência dos hormônios sexuais sobre o desenvolvimento dos bezerros, que se acentua a partir da fase pré-puberal, quando o ganho de peso dos bezerros machos é nitidamente superior ao das fêmeas.

Neste trabalho, os bezerros receberam, além do leite materno, apenas quantidades limitadas de alimento sólido. Provavelmente, o nível de energia ingerido não possibilitou aos machos manifestarem o possível maior potencial para ganho de peso durante a fase de aleitamento.

Os bezerros filhos das vacas mestiças F1 EuropeuZebu tiveram maior $(\mathrm{P}<0,05)$ peso ao nascer, ganho de peso no período de aleitamento e peso à desmama ajustado para 210 dias que os bezerros das vacas Nelore (Tabela 4).

O melhor desempenho dos bezerros de vacas mestiças deveu-se em grande parte ao efeito da heterose. As progênies de vacas F1 Europeu-Zebu capitalizam 100\% de heterose materna, que se reflete em maior peso ao nascer, maior produção de leite das mães e maior taxa de sobrevivência (Koger, 1973; Barbosa, 1990). Neste trabalho, são ainda beneficiadas pelo efeito aditivo dos genes das raças paternas das mães, que confere aos bezerros os potenciais para ganho de peso mais elevados, característica das raças Limousin e Simental, e confere às mães (vacas F1) o maior potencial de produção de leite, especialmente no caso das vacas F1 Simental-Nelore. Os bezerros filhos das vacas Nelore, por outro lado, não apresentam heterose individual e não se beneficiam da heterose materna, que, segundo Koger (1973), provoca a maior parte do aumento do peso de bezerros desmamados quando se utilizam os cruzamentos.

Além dos benefícios da heterose materna e do efeito aditivo de genes proporcionado pelas mães mestiças, os bezerros filhos das vacas F1 possuem heterose individual que atinge $100 \%$, no caso dos bezerros “tricross", filhos das vacas LN (1/2 Brahman $1 / 4$ Limousin $1 / 4$ Nelore), e $50 \%$ no caso dos bezerros retrocruzados, filhos das vacas SN (3/4 Simental 
Tabela 4 - Níveis de probabilidade para o erro tipo I associados aos contrates ortogonais entre bezerros filhos de vacas Nelore e mestiças $(\mathrm{N} \times \mathrm{M})$ e entre filhos de vacas F1 Nelore-Simental e F1 Nelore-Limousin $(\mathrm{SN} \times \mathrm{LN})$, para características relacionadas ao peso vivo, médias para os diferentes grupos genéticos

Table 4 - Levels of probability for error type I, associated to orthogonal contrasts between calves from Nellore and crossbred cows $(N \times C B)$ and between calves from F1 Simmental-Nellore and Limousin-Nellore cows $(S N \times L N)$ referring to traits related to live weight, means for the different genetic groups

\begin{tabular}{|c|c|c|c|c|c|c|}
\hline \multirow[t]{2}{*}{ Item $^{1}$} & \multicolumn{2}{|c|}{$\begin{array}{l}\text { Nível de probabilidade para os contrastes } \\
\text { Level of probability for contrasts }\end{array}$} & \multicolumn{4}{|c|}{$\begin{array}{l}\text { Quadrado mínimo, erro-padrão coeficiente de variação } \\
\text { Least square mean, standard error and coefficient of variation }\end{array}$} \\
\hline & $\mathrm{N} \times \mathrm{M}$ & $\mathrm{SN} \times \mathrm{LN}$ & $\mathrm{N}$ & $\mathrm{SN}$ & $\mathrm{LN}$ & CV (\%) \\
\hline GPD, g (DWG) & $<0,0001$ & 0,4241 & $524,2 \pm 31,6$ & $724,7 \pm 35,6$ & $687,0 \pm 30,0$ & 16,43 \\
\hline $\mathrm{PD}_{210}, \mathrm{~kg}\left(W T_{210}\right)$ & $<0,0001$ & 0,2379 & $138,8 \pm 6,5$ & $187,1 \pm 7,4$ & $175,5 \pm 6,2$ & 13,11 \\
\hline
\end{tabular}

${ }^{1}$ em que (given): PN - peso ao nascer (birth weight); GPD - ganho de peso diário (daily weight gain); $\mathrm{PD}_{210}$ - peso à desmama corrigido para 210 dias de idade (Weaning weight adjusted to 210 days of age).

$1 / 4$ Nelore), que lhes confere maior potencial para ganho de peso (Barbosa, 1990). O conjunto de todos os fatores genéticos favoráveis explica o melhor desempenho dos bezerros filhos das vacas mestiças em relação aos bezerros Nelore.

Entre as progênies das vacas LN e SN, não houve diferença $(\mathrm{P}>0,05)$ quanto aos pesos ao nascer e à desmama e ao ganho de peso durante a fase de aleitamento. O comportamento semelhante das progênies das vacas dos dois grupos sugere que a maior heterose individual dos filhos das vacas LN (100\%) em relação aos bezerros das vacas SN (50\%) foi contrabalanceada pela maior produção de leite das vacas SN e possivelmente pelo maior potencial de ganho de peso (efeito aditivo) da raça Simental em relação a Brahman, raças paternas dos bezerros.

Nas condições deste trabalho, pressupõe-se que o nível de produção de leite da vaca assume papel relevante, uma vez que limitou-se a ingestão diária de alimento sólido pelos bezerros ao mínimo necessário para o adequado desenvolvimento ruminal.

Resultados indicando a estreita relação entre o nível de produção de leite da vaca e o desenvolvimento do bezerro foram relatados por Silva \& Pereira (1986) em avaliação de fêmeas com diferentes graus de sangue Chianina-Nelore $(1 / 2,1 / 4$ e $5 / 8)$, os quais evidenciaram que os bezerros filhos das vacas de maior produção de leite tiveram melhor desempenho.

A superioridade dos mestiços observada neste trabalho foi também verificada por Barcellos \& Lobato (1992) em ensaio conduzido com animais Hereford e mestiços F1 Hereford-Nelore e 3/4 Hereford-Nelore. Os bezerros 3/4 Hereford apresentaram ganho de peso até a desmama 21,6\% maior que os Hereford, enquanto os F1 ganharam 16,0\% mais peso que os puros. Esses resultados reafirmam ainda a importância preponderante da heterose materna no desempenho da progênie, na fase de aleitamento. Bezerros $3 / 4$ têm $100 \%$ de heterose materna e 50\% de heterose indivi- dual, enquanto os $\mathrm{F} 1$ possuem $100 \%$ de heterose individual mas não se beneficiam da heterose materna.

Avaliando animais mestiços Limousin-Nelore e Charolês-Nelore, Alencar et al. (1994) não observaram diferenças quanto aos pesos ao nascimento e à desmama entre os dois grupos. Por outro lado, Souza et al. (1994), avaliando os pesos à desmama de produtos de vacas Nelore com touros Nelore, Brangus, Simental, Canchim, Gelbvieh, Angus, Brangus Vermelho e Gir, verificaram diferenças entre vários grupos genéticos com destaque para os filhos de touros Gelbvieh, Angus e Simental. Essas três raças paternas distanciam-se mais geneticamente que as demais da raça Nelore, o que eleva a heterose potencial da progênie e justifica os resultados.

\section{Conclusões}

A habilidade materna em vacas mestiças, expressa em maior produção de leite e em maior peso da progênie ao nascer, que refletem em maior peso à desmama dos bezerros, é maior que em vacas Nelore. Não há diferenças entre as vacas de corte Nelore e mestiças Europeu-Zebu quanto à forma da curva de lactação, no entanto, os dois grupos diferem quanto à persistência da lactação.

\section{Agradecimento}

Ao pós-graduando Thiago Vasconcelos Melo e ao zootecnista Cláudio Teixeira Lombardi, pela colaboração na condução do experimento.

\section{Literatura Citada}

ALENCAR, M.M.; JUNQUEIRA FILHO, A.A.; PARANHOS, N.E. Produção de leite em vacas da raça Canchin. Revista da Sociedade Brasileira de Zootecnia, v.14, n.3, p.358-366, 1985. 
ALENCAR, M.M. Efeitos da produção de leite sobre o desenvolvimento de bezerros Canchim. Revista Brasileira de Zootecnia, v.16, n.1, p.1-13, 1987.

ALENCAR, M.M.; RUZZA, F.J.; PORTO, E.J. et al. Desempenho produtivo de fêmeas das raças Canchim e Nelore. III. Produção de leite. Revista Brasileira de Zootecnia, v.17, n.4, p.31728, 1988.

ALENCAR, M.M. Relação entre produção de leite da vaca e desempenho do bezerro nas raças Canchin e Nelore. Revista da Sociedade Brasileira de Zootecnia, v.18, n.2, p.146$156,1989$.

ALENCAR, M.M.; LIMA, R.; OLIVEIRA, J.A.L. Pesos ao nascimento, à desmama e ao sobreano de animais cruzados Limousin-Nelore e Charolês-Nelore. In: REUNIÃO ANUAL DA SOCIEDADE BRASILEIRA DE ZOOTECNIA, 21., 1994, Maringá. Anais... Maringá: Sociedade Brasileira de Zootecnia, 1993. p.152.

BARBOSA, P.F. Cruzamentos para produção de carne bovina no Brasil. In: PEIXOTO A.M.; MOURA, J.C.; FARIA, V.P. (Eds.). Bovinocultura de corte: fundamentos da exploração racional. 1.ed. Piracicaba: Fundação de Estudos Agrários Luiz de Queiroz, 1990. p.459-511.

BARCELLOS, J.O.J.; LOBATO, L.F.P. Efeito da época de nascimento no desenvolvimento de bezerros Hereford e suas cruzas. I. Peso ao nascer e ganho médio diário pré-desmama. Revista Brasileira de Zootecnia, v.2, n.1, p.137-149, 1992.

CALEGARE, L.N.P. Exigências e eficiência energética de vacas de corte Nelore e de cruzamentos Bos taurus $x$ Nelore. Piracicaba: Escola Superior de Agricultura Luiz de Queiroz, 2004. 79p. Dissertação (Mestrado em Agronomia) Escola Superior de Agricultura Luiz de Queiroz, 2004.

CUBAS, A.C.; PEROTTO, D.; ABRAHÃO, J.J.S. et al. Desempenho até a desmama de bezerros Nelore e cruzas com Nelore. Revista Brasileira de Zootecnia, v.30, n.3, p.694-701, 2001.

CUNDIFF, L.V.; GREGORY, K.E.; SCHWEST, F.J. et al. Effects of heterosis on maternal performance and milk production in Hereford, Angus and Shortorn cattle. Jounal of Animal Science, v.38, p.728-745, 1974.

DAWSON, W.M.; COOK, A.C.; KNAPP JR., B. Beef Production of beef shorthorn cows. Journal of Animal Science, v.19, n.3, p.502-508, 1960.

EUCLIDES FILHO, K.; FIGUEIREDO, G.R.; EUCLIDES, V.P.B. Eficiência de produção de vacas de corte com diferentes potenciais para produção de leite. Pesquisa Agropecuária Brasileira, v.30, n.7, p.1003-1007, 1995.

FERRELL, C.L.; JENKINS, T.G. Efficiency of cows of different size and milk production. Germoplasma Evaluation Program. Clay Center: US MARC - ARM. 1982. p.12-19. (Progress Report, Nc-2, 10).

FONTES, C.A.A. Effects of creep feeding, zeranol and breed type on reproduction and maternal ability of beef cows. Gainesville: University of Florida, 1985. 123p. Tese (PhD in Animal Science) - University of Florida, 1985.

JEFFERY, N.B.; BERG, R.T.; HARDIN, R.T. Factors influencing milk yield of beef Cahle. Journal of Animal Science, v.51, n.3, p. 551-560, 1971.

JENKINS, T.G.; CUNDIFF, L.V.; FERRELL, C.L. Differences among breed crosses of cattle in the conversion of food energy to calf weight during the preweaning interval. Journal of Animal Science, v.69, n.7, p.2762-2769, 1991.

JENKINS, T.G.; FERRELL, C.L. A note on lactation curves of crossbred cows. Animal Production, v.39, p.479-484, 1984.

JENKINS, T.G.; FERRELL, C.L. Lactation characteristics of nine breeds of cattle fed various quantities of dietary energy. Journal of Animal Science, v.57, n.6, p.1652-1660, 1992.

JENKINS, T.G.; FERRELL, C.L.; ROBERTS, A.J. Lactation and calf weight traits of mature crossbred cows fed varying daily levels of metabolizable energy. Journal of Animal Science, v.78, n.1, p.7-14, 2000.
JENKINS, T.G.; FERRELL, C.L. Preweaning efficiency for mature cows of breed crosses from tropically adapted Bos indicus and Bos taurus and unadapted Bos taurus breeds. Journal of Animal Science, v. 82, n.5, p.1876-1881, 2004.

KOGER, M. Summary. In: KOGER, M.; CUNHA, T.J.; WARNICH A.C. (Eds.). Crossbreeding beef cattle. 2.ed. Gainesville: University of Florida Press, 1973. p.434-447.

MELTON, A.A.; RIGGS, J.K.; NELSON, L.A. et al. Milk production, composition and calf gains of Angus, Charolais and Hereford cows. Journal of Animal Science, v.26, n.4, p.804-809, 1967.

NATIONAL RESEARH COUNCIL - NRC. Nutrient requirements of beef cattle. 7.ed. Washington, D.C.: National Academic of Sciences, 2000. 248p.

NEVILLE, W.E.; WARREN JR., E.P.; GRIFFEY, W.A. Estimates of milk production in Hereford cows. Journal of Animal Science, v.38, n.1, p.1-8, 1974.

NOTTER, D.R.; CUNDIFF, L.V.; SMITH, G.M. et al Characterization of biological types of cattle. VII. Milk production in young cows and transmitted and maternal effects on preweaning growth of progeny. Journal of Animal Science, v.46, n.4, p.908-921, 1978.

OLIVEIRA, V.C. Eficiência de utilização da energia alimentar para a produção de bezerros por vacas Nelores e mestiças. Campos dos Goytacazes: Universidade Estadual do Norte Fluminense, 2006. 60p. Dissertação (Mestrado em Produção Animal) - Universidade Estadual do Norte Fluminense, 2006.

PEACOCK, F.M.; KIRK, W.G.; KOGER, M. et al. Evaluation of the Brahman breed as straightbred and crossbred for beef production in South Cewntal Florida. Gainesville, Florida Agricultural Experiment Station, 1977 (Technical Bulletin, 790).

RESTLE, J.; SENNA, D.B.; PACHECO, P.S. et al. Grupo genético e heterose na produção de leite de vacas de corte submetidas a diferentes sistemas de alimentação. Revista Brasileira de Zootecnia, v.34, n.4, p.1329-1338, 2005.

REYNOLDS, W.L.; DEROUEN, T.M.; BELLOWS, R.A. Relationships of milk yield of dam to early growth of straighbred and crossbred calves. Journal of Animal Science, v.47, n.2, p.584-592, 1978.

REYNOLDS, W.L.; DEROUEN, T.M.; MEYERHOEFFER. Milk production of Angus, Brahman and Zebu cross cows. Journal of Animal science, v.26, n.1, p.206 (Abstr.), 1967.

ROBISON, O.W.; YUSUFF, M.K.M.; DILLARD, E.U. Milk production in Hereford cows. I. Means and correlations. Journal of Animal Science, v.47, n.1, p.131-136, 1978.

ROSADO, M.L. Características reprodutivas, produtivas e biométricas de fêmeas Nelore e F1 Europeu-Nelore. Viçosa, MG: Universidade Federal de Viçosa, 1991. 108p. Dissertação (Mestrado em Zootecnia) - Universidade Federal de Viçosa, 1991.

RUTLEDGE, J.J.; ROBISON, O.W.; AHLSCHWEDE, W.T. et al. Milk yield and its influence on 205-day weight of beff calves. Journal of Animal Science, v.33, n.3, p.563-567, 1971.

SILVA, M.A.; PEREIRA, F.A. Crescimento e desempenho reprodutivo de animais zebu e mestiços. Chianina-zebu. Revista da Sociedade Brasileira de zootecnia, v.15, n.2, p.116123, 1986.

SOUZA, J.C.; FERRAZ FILHO, P.B.; VALENCIA, E.F.T. et al. Estudo comparativo de peso ao desmame de bezerros filhos de touros zebu e europeu. In: REUNIÃO ANUAL DA SOCIEDADE BRASILEIRA DE ZOOTECNIA, 21., 1994, Maringá. Anais... Maringá: Sociedade Brasileira de Zootecnia, 1993. p.181.

WILLHAM, R.L. Beef milk production for maximum efficiency. Nutrition Animal Science, v.34, n.5, p.864-869, 1972. 